\title{
INTENTIONALITY AND CONTINUITY OF EXPERIENCE
}

\author{
ANDRÉ LECLERC
}

\begin{abstract}
My aim is to provide an analysis of cognitive experience from the point of view of philosophy of mind, by identifying and describing different components or features present in it. But different things are called 'experience' and some are more complex than other. I will first examine different uses of the word 'experience' to clear the way and to avoid cases of circularity. Then I try to restrict the investigation and introduce the mode (character) and content of experience, and take BonJour's suggestion of what cognitive experience is as a starting point. In my view, the two main features of experience are Horizontal Intentionality (which produces Phenomenal Continuity) and Vertical Intentionality. The first is the most striking and fundamental; it constitutes the continuity of experience. Vertical Intentionality selects objects of experience, so that our experience is always experience of something. In Perception, something is identified and recognized by the application of concepts. Attention is required, especially when we get involved in complicated operations or manipulations. Finally, the last feature is constituted by a huge set of dispositions, particularly abilities to keep track our thoughts and former experiences. Cognitive Experience in the full sense is the result of the interaction and mutual support of these features.
\end{abstract}

Keywords: Experience; intentionality; phenomenal continuity; dispositions.

\section{Introductory Remarks}

How do we acquire knowledge of nature, society, history? Classical Empiricists, famously, answered: "by experience", or through processes that involved experience, whatever that means. But what is experience? If the first answer sounds trivial today, the answer to the second question is not.

I don't have great epistemological ambitions here. My aim is to present a partial analysis of experience in general, and cognitive experience in particular, from the point of the Philosophy of Mind and Phenomenology, or a "correct description" of its main traits. Analytic philosophy and phenomenology share a metaphilosophy according to which the philosopher's job is to describe, not to explain. But, as I shall defend, 'experience' is precisely a first-person term and experience certainly belong to the realm of phenomenology. So, I will try to provide a consistent and economical description of experience. Any explanation of what we experience and how we experience changes in our own body or what happens in it, would take us far beyond the scope of phenomenology or of any study of experience from a first-person point of view. I will insist on the dynamic aspects of experience, because I believe they have been neglected, most of the time, by analytic philosophers. But pragmatists (James,

Principia 21(2): 235-249 (2017).

Published by NEL — Epistemology and Logic Research Group, Federal University of Santa Catarina (UFSC), Brazil. 
Dewey) and phenomenologists (Brentano, Husserl, Merleau-Ponty), even a classical empiricist like Hobbes, ${ }^{1}$ took continuity and succession to be the main characteristic of experience.

I am an intentionalist, that is, someone who accepts at least the first part of Brentano's thesis, that intentionality is the mark of the mental. No surprise, I will put in the forefront two basic features of experience: vertical intentionality, and continuity, which I try to understand in terms of horizontal intentionality. Horizontal intentionality is especially important for the analysis of the "internal consciousness of time". It is, as we shall see, a network of intentionality operating at a sub-personal level.

I am also a dispositionalist. I believe that a large part of mentalistic vocabulary is dispositional. Propositional attitudes, tastes, inclinations, habits, abilities of all sorts and basic mental capacities (like face recognition) are certainly dispositions. But mental acts (like judging, deciding, etc.) and mental events (involuntary remembrances, sensations and feelings of all sorts) depend on the possession of capacities and $^{\text {abilities. }}{ }^{2}$

Experience itself, in the sense I will elect below, is clearly a dynamic process, the succession of multiple and simultaneous processes of sensorial impressions, and a correct theoretical representation of it should involve dynamics models. But the continuity of experience should also be understood as involving a certain amount of stability in a twofold sense. First, stability of the "world of experience", because in an ever-changing world we would be unable to make simple inductions and such a world would be a never-ending source of perplexity. The funny example of Rip van Winkle gives us an idea of what would happen if almost everything around us suddenly ceases to look familiar, and when we stop tracking orderly our thoughts and past experiences. And second, stability on the part of the cognitive agent, who must be roughly the same agent, day after day, and that stability can only be secured by a huge set of dispositions acquired over the years.

I will first consider different uses of the word 'experience' in order to clear the way and define better the relevant concept of this ongoing investigation. Then I will distinguish different traits or components in the very notion of experience. Finally, I will examine each one of these components briefly.

\section{'Experience'}

Many things are called 'experience'. I would like to suggest the following umbrella term: in the broadest sense, 'experience' denotes the continuous succession of mental states and mental events belonging to one single first-person perspective. Hobbes once called "mental discourse" or "train of thoughts" that continuous succession, and

Principia 21(2): 235-249 (2017). 
James and Husserl later called it "stream of consciousness" (Bewusstseinsstrom). This is an all-inclusive sense of 'experience' which includes dreams as well as cognitive experience.

There are highly subjective types of experience, like 'mystical experience', 'ecstatic experience', 'emotional experience', 'literary experience', 'Tantra experience', and so on. They are all experiences in that broad sense of the word, that is, they are all included in (and presuppose) the stream of consciousness.

There are wholly objective uses, like 'scientific experience'. These should be set aside. In many languages, like French and Portuguese, we use the same word for experience and experiment (though in Portuguese we also use 'experimento'). But sometimes we do so even in English. Of course, wherever it is possible (as in English and German), we should not use 'experience' in place of 'experiment'. Be that as it may, there is an objective sense of 'experience' in which an experience is something repeatable, by different people at different moments or places, with a well-defined protocol and determined parameters. 'Experiment' is a much better word for these scientific tests; so, we speak of the 'Michelson-Morley experiment', the 'Puy-de-Dôme experiment', etc.

In a less objective sense, we also speak of 'thought experiments' (from German Gedankenexperiment). In these cases, it is not always easy to agree on the conclusions. Intuitions and imagination get into the picture. But we still use a common script that everyone follows in the thought experiment. Many people are convinced that two tokens of 'That water looks fresh' uttered by someone on Earth and by her Doppelganger on Twin-Earth do not express the same thought. But some people disagree and do not share the same intuitions.

There are other uses that Gupta (2006) calls "thick" uses of 'experience,' when it is applied to collectivities, nations or countries. Thus, we can hear people talking about "the American democratic experience", or "the Labour Party experience at 10 Downing Street", etc. In these case, 'experience' denotes something shared by many people, each one with his/her own first-person perspective. These uses do not refer to first-person experience. They presuppose first-person experiences and, in that sense, they are not "basic". They are linguistic short cuts used by historians or sociologists in their descriptions of social processes.

When we say that someone is 'experienced' or 'has experience' in such and such domain of activity, we mean that that person is apt to judge quickly and correctly a situation, or to identify and resolve a problem. Part of the problem of specifying the meaning of 'cognitive experience' stems from the fact that many things are called 'experience'. To have a cognitive experience, we shall see, we need to apply concepts and make judgments of similarity. In my view, to be experienced in that sense is an essential presupposition for having any new cognitive experience. This sounds a bit circular, but I believe that we are speaking of different kinds of experiences. To be 
experienced is to have acquired dispositions (like concepts, abilities, ways to identify and to solve problems, etc.), and dispositions are neither objects of experience nor experienced. When we acquire a new piece of empirical knowledge, not by testimony, but rather by being an active agent directly in contact with the phenomenon, sensorial experience would be an essential part of it, but that acquisition always presupposes that the agent is somehow "experienced", has concepts to identify the phenomenon. The mind of a knower is not a tabula rasa. Then it may seem that we are going in a circle, using experience for understanding experience. But these are related but different things with similar names. So, there is no circularity involved in saying that sensorial experience is part of cognitive experience. Similarly, we cannot have a new cognitive experience without "being experienced", that is, without having acquired a repertoire of concepts, beliefs and quite a lot of other dispositions.

\section{Experiences: What they are}

There are mental states (e.g. propositional attitudes), mental acts (deciding, judging) and mental events (seeing, hearing, touching, tasting, perceiving, involuntary remembering, etc.). As a first approximation, experiences in general belong to the third category. They are mental events, and like any event, they have a duration. However, most of the time, the temporal boundaries are not very well defined.

We must distinguish what has been called the mode or character of an experience and its content. The mode could be described by the use of the standard formula: of any experience, we can say "there is something it is like to have it". We all make the difference between feeling a headache, a stomachache, an orgasm, an aesthetic emotion, a visual experience, a tactile experience, an auditory experience, the taste of chocolate and the taste of orange juice, etc. The content is what the experience represents. The content is part of the experience. It is usually specified by an expression (a nominal or verbal syntagma, or a full sentence) in the scope of a verb denoting a mental event. When I hear that Glenn is playing piano, and then I see that Glenn is playing piano, I have two different experiences, but is the content the same? I would say yes, as long as the content is something we specify by the use of a sentence of a public language. That is not to say that the content is linguistic in nature. It only means that there is no other way to do that. Of course, I can have the experience of seeing Glenn playing piano without hearing the concerto, and I can hear Glenn playing piano without seeing the virtuoso. Both experiences may serve to justify the belief that Glenn is playing piano. But the difference is due to the mode, not to the content. As to the intentional object, is it the same? We will be back to that question later on.

Cognitive experience is a variety of experience. It is something complex, with

Principia 21(2): 235-249 (2017). 
different features. Methodologically, I believe we should adopt a liberal approach. The application of the concept EXPERIENCE is not an all or nothing affair. Experience itself is something that comes in degrees.

I would like to start with a broad notion of cognitive experience. I think Laurence BonJour's suggestion is interesting as a start:

My suggestion ... is that the relevant notion of experience should be understood to include any sort of process that is perceptual in the broad sense of (a) being a causally conditioned response to particular, contingent features of the world and (b) yielding doxastic states that have as their content putative information concerning such particular, contingent features of the actual world as contrasted with other possible worlds. [...] And thus not only sense experience, but also introspection, memory, kinesthesia, and clairvoyance and telepathy (should these exist) would count as varieties of experience and the justification derived therefrom as a posteriori. (BonJour 1998, p.8)

Thus understood, 'cognitive experience' is clearly a first-person subjective term. But this does not mean that experiences in that sense are not sharable or linguistically representable. Of course, most of the time, they are. BonJour's suggestion, correctly, excludes dreams and the simple humming of a melody, processes that do not involve perception "in the broad sense". But as long as we limit ourselves to cognitive experience, it serves as a good starting point.

I believe most of the five components or features listed here are present in the empiricist tradition. But I am not interested here in the normative dimension of the empiricist concept EXPERIENCE. Especially, I am not interested in the concept EXPERIENCE as denoting a kind of legal instance necessary for validating our pretensions to knowledge. That normative dimension appears clearly in Hobbes, Hume, Condillac, and Mach, and it served to disqualify as meaningless concepts and terms like those of the scholastic tradition, like "haecceity" or "quiddity". Verificationism plays a similar role in contemporary empiricism. As I said, I want to look at experience from the point of view of philosophy of mind, not from the point of view of normative epistemology. One important difference between a certain empiricist tradition and my approach is the absence of sense data. Nothing like sense data are objects of thought or of our memories. In some special circumstances a sensorial quality may become an intentional object; we can pay attention to such qualities, but this does not mean that we can translate what we say about objects in sentences about sense data.

We can distinguish different components or features in what we call 'cognitive experience'. Cognitive experience, I suggest, involves the following characteristics which, when they are all put together, result in a cognitive experience in the strongest degree. These features are: A) phenomenal continuity or horizontal intentionality, 
involving sentience or sense impression (or awareness); B) attention; C) perception and recognition; D) vertical intentionality; and finally, E) the capacity to keep track of our thoughts (in the sense of Kaplan's cognitive dynamics) and previous experiences, and the ability to make judgments of similarity.

'Cognitive experience' in the full sense denotes the result of the mutual support of these features. I will explain how these characteristics relate one to another. To have a cognitive experience in the full sense of the word involves all these items. But it is possible to be awake without paying attention to anything special around us, or without perceiving and recognizing what we see, etc. These features, usually, are not independent, and some are more fundamental than others. I believe the two main kinds of intentionality unveiled in classical phenomenology, vertical and horizontal intentionality, are the most fundamental. The first is like a spear thrown in the direction of an object; most of the time, it selects one object at a time (or a small group of objects, or a feature, an event, etc.). Horizontal intentionality is still more fundamental: it constitutes the continuity of our experience, its tissue so to speak, and gives it consistency.

The identity of a cognitive agent over time depends also upon a huge set of dispositions. When I wake up in the morning, I am the same agent as I was the day before, because I have the same dispositions, that is, the same tastes, the same inclinations, the same competences, the same capacities and abilities, the same tendencies, the same concepts, etc. But dispositions are not "phenomenal" in character. We do not "experience" our capacities and abilities; we exercise or apply them, but it is only through this exercise that we can have something like a cognitive experience.

So, in the relevant sense, 'experience' is a first-person term. It is subjective, that is, experiences need a bearer. But there is a difference between hearing a tune and humming the same tune 'just in your head'. Humming a tune is not having a real experience of hearing; it is a quasi-hearing, not a real hearing. But is it an experience? I do not pay attention to the buzz of the refrigerator in the kitchen. I realized it was there all the time only when it stops. Is this really an experience of hearing? Is dreaming a kind of experience? What about having an afterimage? All these "marginal" cases can take place in the same "stream of consciousness". They are all experiences, according to our all-inclusive sense. Cognitive experience is a special case which involves, always, a causal transaction with the world (sensorial impressions) and the application of concepts.

\section{A. Phenomenal Continuity of Awakeness}

The first feature is Phenomenal continuity. It has been pointed out by William James and Husserl as a central characteristic of experience. The stream of consciousness

Principia 21(2): 235-249 (2017). 
(James) or Bewusstseinsstrom (Husserl) is continuous, except when we are in a deep dreamless sleep. It starts over every day when we wake up and stops when we fall asleep again. By 'continuous' here I mean "sensibly continuous". ${ }^{3}$ When awake, there is no gaps detectable at the phenomenal level, no abrupt ruptures in our experience, and it doesn't stop unless we pass out, get anesthetized or fall deeply asleep.

It is hard to imagine what would be a "gappy" experience. A "stroboscopic experience" could still be an experience, or so it seems to me, but the gaps would have to be very short and fast, so that it would still be possible to keep track of the objects. But that would make their re-identification insecure, and we could never be sure they are the same. Be that as it may, our experience is not of that kind, and our internal consciousness of time does not seem to admit gaps (with the exception, of course, of the usual time-gaps, when we fall asleep, or anesthetized, etc.).

When we wake up, we feel sensations in all parts of our bodies. It is hard, may be impossible, to pay attention to all of these sensorial impressions. William James used the expression "swarming continuum" to denote the extraordinary richness of the stream of consciousness. Most of the time there are salient impressions (e.g. a pain), and for us, human beings, visual experience is normally the one to which we pay attention the most. At each moment, we are assailed by a huge amount of sensorial impressions of all sorts, and at each moment, so to speak, we "live in" that total concrete state of consciousness.

According to James, continuity here means two things: 1) "That even when there is a time-gap the consciousness after it feels as if belonged with the same consciousness before it, as another part of the same self" (1961, p.158); that is, when we wake up, there is nothing strange about what we feel, it is like a new chapter of the same biography and we just carry on as usual; 2) "That the changes from one moment to another in the quality of the consciousness are never absolutely abrupt". (1961, p.158)

Husserl offered a way to conceive of that continuity, to show how it is constituted, with the reticulum of time. Here the description points to structural elements. That continuity presupposes a structure of retention and protension working at a subpersonal level. There is a fusion or synthesis of the present moment with the next one and with the last one, and that synthesis is not active, does not depend upon any initiative of the cognitive agent. It is a passive synthesis. The traditional paradigm of a temporal object is a melody. When we are hearing music, the tone we are hearing now is not "erased" immediately or taken from our consciousness. Our perception goes further than the momentaneous hearing of a tone. And this is true of any kind of perception. ${ }^{4}$ The living present, the living 'now' or specious present, is not a dimensionless point on a line; it has a certain 'thickness'. Husserl agreed with James on that score. Apparently, Husserl knew The Principles of Psychology and found there some interesting ideas. In Psychology: Briefer Course, James says that "[t]he sensible present 
has duration". (p.266). Where Husserl talks of "halo of time" (Zeithof), James says that the sensible present has "fringes". The succession of moments forms a mental synthesis which is passive and does not depend upon attention or any explicit mental act. Without that continuity, there wouldn't be a world of objects around us, and there wouldn't be experience at all. That continuity constitutes a single perspective on the world, that of a cognitive agent. An experience is always someone's experience. So, phenomenal continuity and personal identity are closely related. ${ }^{5}$

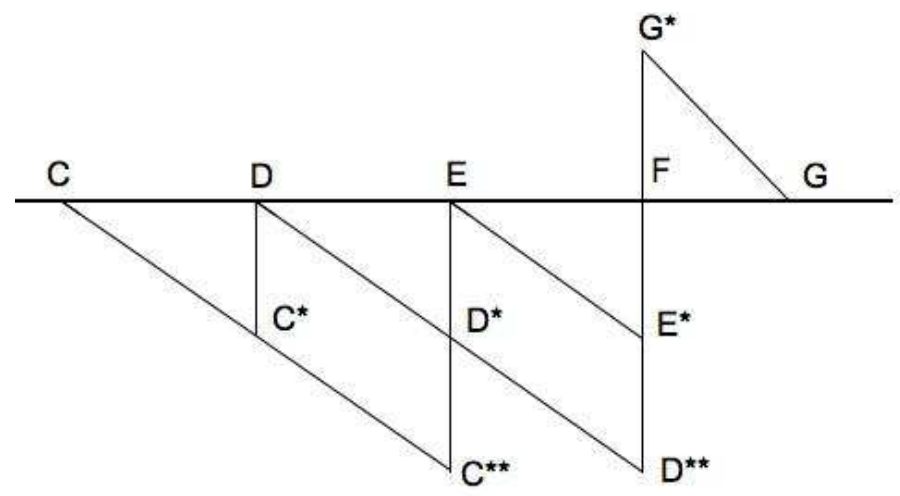

Figure 1: HUSSERL'S RETICULUM OF TIME. (The horizontal line $C-G$ represents the "nows" of sensorial impression of the tone $C, D$, etc.; below are the retention of the tone heard, like $C^{*}$ and $D^{*}$; and then the retention of the retention of the tone heard, that is, $C^{* *}, D^{* *}$. Above the $C-G$ line, $G^{*}$ is the protension of $G$ to be heard one moment later.)

At $C$, we are hearing a tone; at $C^{*}$, we have the retention of $C$; at $C^{* *}$, we have the retention of the retention, etc. And at $F$, we are anticipating the next tone, $G^{*}$. The same structure of retention-protension is at work when different profiles are seen as being profiles of the same object. And again, it works at a sub-personal level.

According to intentionalism, the most basic characteristic of intentional states (acts, events) is their "having an object". ${ }^{6}$ All mental states (acts, events) have an object represented. But a representation is not always conceptual or propositional. It can be sensorial. The hearing of a melody provides a good example. After the moment of sensorial impression of the sound just heard, we have a first retention of that sound (which is the intentional object of that first retention), and then the retention of the retention of that sound (which is the intentional object of the second retention), etc.

$$
\operatorname{Ret}\{\operatorname{Ret}\{\operatorname{Ret}\{\text { Sound }\}\} \text {... }
$$

Sequences like this enables us to anticipate the next sound in a movement of constant protension. We all know how frustrating it is to hear a sound we do not an- 
ticipated because the pianist made a mistake while playing our favorite song. At each new step in the succession of retention, the intentional object change (Ret $\{$ Sound\} is the intentional object of $\operatorname{Ret}\{\operatorname{Ret}\{$ Sound $\}$, and so on.) Otherwise, we could never grasp the melody completely or form the consciousness of it as a temporal intentional object. One moment follows the previous one according to what Husserl (1939) called the Laws of Association according to Analogy. Changes are noticed against a background of similarities; heterogeneities only appear against a homogeneous background. Obviously, a common core must be preserve from one moment to the next. Otherwise, there wouldn't be nexus in the sequence of "nows", each "now" representing a total concrete state of consciousness. Otherwise, there wouldn't be any consistency at all in our experience.

Two observations to conclude this section: 1) It is important to note that the object of retention is never a bunch of sense data. Generally speaking, we remember objects (bodies, events, situations, etc.), and not sense data. And 2) when we talk of 'retention' in this context, it has to do with perception, not memory.

\section{B. Attention}

By 'attention' is meant the capacity to focus on one single object, or property (or process, event, etc.). In a noisy crowd, for example, we are able to exclude every distraction, to focus on the only conversation that interests us. "Attention is what you use to drown out distracting sights and sounds, to focus on whatever it is you need to focus on". ${ }^{7}$ There wouldn't be perception without sensorial impression and attention is a selection of a small part of what we perceive.

In a familiar environment, we perceive and identified easily things to which we do not even pay attention. Attention is required for any delicate manipulation, for any process with a definite expected result, when we are learning something complex or when we are applying rules for the first time. But no one can concentrate or focus for a very long time. Even when we do something that requires attention, like driving a car, we perform a lot of habitual actions without which we could not be competent drivers. So, 'attention' is clearly a term which admits degrees. But, at some degree, it is a necessary component of experience. At any rate, it is through attention that the mind can select its objects in the "swarming continuum" of experience.

Shared attention became especially important recently. If Davidson is right, triangulation involving a "teacher", an "apprentice", and a common situation, is at the root of the acquisition of concepts and meanings. If this is correct, shared attention is the first fabric of concepts and meanings later applied in any cognitive activity.

Principia 21(2): 235-249 (2017). 


\section{Perception and Recognition}

BonJour talks of a perceptual process "as being a causally conditioned response to particular, contingent features of the world". But here there are many distinctions to be made. There are many causal processes on and in my body occurring at the same time, and we cannot pay attention to most of the stimuli we receive or to what we feel all the time; if we try, we experiment something a bit chaotic, a mosaic unified only by one single perspective on the world. That point of view or perspective on the world is what it is to have a mind, a characteristic we have in common with other sentient beings. But human mind is more complex because we have the capacity to acquire a very huge set of dispositions like concepts, beliefs, habits and thoughts. This is why a simple visual experience is not a full-blooded perception. It does not have a conceptual content. What is seen is not identified. This is Dretske's well-known notion of non-epistemic seeing. ${ }^{8}$ But what about dreams and quasi-perception (quasi-vision, quasi-audition, etc.)? In dreams, concepts are applied, and in imagination too, but the element of sense impression is apparently absent. So, they do not count as cognitive experience, at least not in a "strong sense".

A simple visual experience is not a perception, because, in perception, something is identified, that is, concepts are applied. The identification-recognition does not need to be an intellectual process of grasping a function and applying it to a particular; it is enough that something be seen as familiar. We have a simple visual experience and not a full-blooded perception when we see something for which we don't have any readily concept. Probably, something like this happened when the natives of the New World look for the first time to the invaders' caravels. And what is it to misperceive? Simply to apply the wrong concept to what is seen. Recently, I misperceived a bucket for a cat, and famously, Oliver Sacks told us the story of a man who misperceived his wife for a hat! The possession of a concept does not secure the identification of an object. I have the concept VOLTMETER, but I am not sure I would be able to pick up one in the middle of other instruments.

\section{Vertical Intentionality}

Considered abstractly, Intentionality is a relational property instantiated by public representations like sentences, maps, etc., and, of course, by mental representations. Usually, the term is used to denote the power of the mind to represent. Intentionality has been used initially by Brentano as the mark of the mental. The idea of having an object as the fundamental characteristic of mental states, acts or events still raises many questions.

There have been a lot of discussions about the ontological status of intentional

Principia 21(2): 235-249 (2017). 
objects. Do they have a common nature? Do they exist only as long as we think about them? Are they ordinary objects? What about intentional objects that do not exist in tri-dimensional space?

Intentional objects are simply objects of our thoughts; they don't have a common nature, except for the relational (and extrinsic) property of being objects of our thoughts. Sometimes, we find them in our immediate environment; but it happens frequently that our thoughts are directed at objects that do not exist. Many people died in the search of the Eldorado. Other objects are created or constructed (like fictional characters). So, there is no set of intentional objects (a set cannot contain objects that exist besides objects that do not).

How is the intentional object determined? According to Chalmers (2004) and Crane (2009), there are two theoretical options here: pure intentionalism (or representationalism), or impure intentionalism (representationalism). Pure intentionalism is the idea that content and content alone determines what the intentional object is. The mode of the intentional state or event does not interfere; only the concepts constituents of the conceptual content serve to identify the object. The other option, impure intentionalism, says that content and mode together determine what the intentional object is. Chalmers and Crane believe that impure intentionalism is the best option and I agree with them. A desire and a belief, for instance, cannot have exactly the same object, because the belief presents a certain state of affairs as effective, actual, as a fact, while a desire or a wish would represent the same state of affairs as only possible, or depending on some condition, not as a fact.

One serious challenge to Brentano's thesis is the following: Sensorial experiences are mental, but are they intentional? Some philosophers believe that pain, for instance, is not intentional. Searle says that a pain is not pain of something or about something. On that score, I take side with the intentionalists Michael Tye and Tim Crane: pains represent a location on or in the body; it is a "topographical representation" (Tye) varying in intensity. They represent changes, sometimes radical changes, like tissue damage on the skin, or an ailment inside the body, sometimes, small changes of intensity. The same holds for orgasms and other sensorial experiences.

Two things indicate that sensorial experiences like pains are in fact intentional: 1) the phantom limb experience, when a pain is felt in the palm of a non-existent hand (by analogy with searching for something that does not exist, like the Eldorado, etc.), and 2) the failure of substitution of co-referential terms: I feel a pain in the tip of my finger; my finger is in my mouth; therefore, I feel a pain in my mouth... This is Ned Block's funny non sequitur. "I feel ..." create an intensional context in the first premise and the conclusion. The substitution doesn't preserve the truth-value of the premise. As is well-known, linguistic reports of intentional states (acts or events) are typically intensional-with-an-s. 


\section{E. Abilities to keep track of our thoughts and to make judgments of similarity}

Rip van Winkle went to the mountain, met someone who gave him something to drink, and fell asleep for twenty years. When he wakes up and returns to his village, he has a hard time to understand what happened. The portrait on the wall of his favourite tavern is now of George Washington, and not of (crazy) King George III; there is a twenty years old Rip van Winkle in the village, his son, completely unknown to him, and almost all his friends died in the Independence War. He still believes that "yesterday" denotes the day before he fell asleep. Rip is lost in time; for him, the following sentences are true: "yesterday, I went to the mountains"; "yesterday, I drank something strange", etc. This is how Washington Irving (1921) describes the effect of this radical change on the mind of poor Rip van Winkle: “... every thing was strange. His mind now misgave him; he began to doubt whether both he and the world around him were not bewitched". (pp.52-53). Also: "Rip's heart died away at hearing of these sad changes in his home and friends and finding himself alone in the world. Every answer puzzled him, too, by treating of such enormous lapses of time, and of matters which he could not understand..." (p.65). Irving's description is fictitious, but nonetheless its psychological plausibility seems to me obvious.

Fortunately, we are luckier than poor Rip van Winkle, and most of the time, we can track easily our thoughts and express the same truth-conditions just by changing parts of a sentences. If I say, "today I drank a very special beer", I can express the same truth-conditions the day after by saying: "yesterday, I drank a very special beer"; the next month, I can say "last month, I drank a very special beer", etc. Rip van Winkle's cognitive dynamics is seriously impaired. There is too much changes for him to swallow at the same time. His world, the one in which everything was looking so familiar, was a pre-revolutionary world, but he woke up in a post-revolutionary world.

My point is that the continuity of experience is not only a matter lasting the time of a musical phrase; as James once more correctly pointed out, it extends over years. When we consider decades or a time-life, there are plenty of time-gaps (regular dreamless deep sleep, or even a period of coma, etc.). We change over years, of course, but the changes should not be too radical. Once again, changes happen against a background of stability, and differences or heterogeneities are detected against a background of homogeneity, as Husserl (1939) once put it. From one moment to the next, homogeneity must always prevail over heterogeneity. This law of association still holds when we consider years. When we wake up in the morning, we are the same cognitive agent as the day before because we have the same dispositions, that is, the same repertoire of concepts, the same knowledge, the same

Principia 21(2): 235-249 (2017). 
abilities, the same competences, the same tastes, inclinations, etc. Dispositions, by definition, are stable (an unstable disposition is no disposition at all). But it takes time to acquire new dispositions (or to lose ones we do not exercise).

I am using a realistic concept of disposition. Molnar (2003) is a good classical exponent of that view. Traditional empiricism never trusted dispositions; they are not objects of experience and any talk about them must be reduced to sentences "disposition-free". (Remember Carnap's "reduction sentences".) The realistic claim is simple: There are dispositions in the natural world (solubility, conductivity, resistance, gravity, etc.). And this includes mental dispositions (abilities, tastes, inclinations, etc.) physically realized in the brain. There are dispositional properties and categorical properties, and the first ones are grounded in the second ones. A dispositional property causes its manifestation when some appropriate conditions are met. And the attribution of a dispositional property presupposes the truth of a conditional counterfactual. Some mental dispositional properties are innate, like the capacity for face recognition, or consciousness itself (according to Lynne Baker), but most are acquired through repetition and training.

My ability to make a judgement today over subjects of my competence requires something that goes beyond phenomenal continuity, like the possession of concepts, and the ability to make judgments of similarity: we apply the same concepts or meanings in situations that must be similar enough, precisely to justify a new application of the same concepts. The situations can be separate by time-gaps (but not too long...), but this doesn't matter. The stability of the dispositions acquired makes sure that they are all parts of the same biography.

\section{Some Conclusions}

We have a world of objects through what we feel, see, touch, taste, hear, or perceive in the "swarming continuum" of the stream of consciousness. This is the whole of our experience. It is 'experience' in the most inclusive and broadest sense. Something is an intentional for us either because it is found and identified in that stream of phenomenal continuum, or because they are constructed therefrom (mathematical objects, fictional characters, cultural objects in general). It is like looking at a rock stuck in a brook while the water goes down steadily. What we call "the same object" is obtain by imposing something stable (concepts, dispositions) against the current. It is almost impossible to pay attention to everything we feel (see, hear, touch, etc.) at any moment. For that reason, attention, to some degree, is necessary; otherwise, our mind could not "have an object". Without attention, there wouldn't be identification and recognition of objects, except when we are in a very familiar environment where nothing has changed, and nothing calls our attention. Cognitive experience presup- 
poses just that: identification and recognition of objects given in the continuum of experience by the application of concepts. Concepts, and dispositions in general, are not objects of experience. But they make possible the acquisition of new knowledge and they make sure that a cognitive agent remains "the same" between two timegaps without getting lost in time. Cognitive experience is in constant reorganization. We cannot stop learning. Scientific knowledge is systematic because it is theoretic. But ordinary knowledge cannot be totally unsystematic. This is possible because the world "contributes" somehow, by offering recognizable patterns and regularities. A world full of irregularities would be a source of perplexities. A world with different laws every day would not be cognizable. Cognitive experience is a negotiation between the constant moving forward of experience and the stability of the world and of our mental dispositions.

\section{References}

BonJour, L. 1998. In Defense of Pure Reason. Cambridge: C.U.P.

Cartwright, N. 2002. What Makes a Capacity a Disposition? Centre for Philosophy of Natural and Social Science. http://personal.Ise.ac.uk/cartwright/PapersGeneral/ what $\backslash \% 20$ makes $\backslash \% 20$ a $\backslash \% 20$ capacity $\backslash \% 20 \backslash \%$ a $\backslash \%$ disposition.pdf.

Chalmers, D. 2004. The Representational Character of Experience. In: The Future for Philosophy. Oxford: Oxford University Press.

Crane, T. 2009. Intentionalism. In: Aspects of Psychologism. Cambridge (MA): Harvard University Press, 2014.

Dainton, B. 2008. The Phenomenal Self. Oxford: O.U.P.

Temporal Consciousness. The Stanford Encyclopedia of Philosophy (Fall 2017 Edition), Edward N. Zalta (ed.). https://plato.stanford.edu/archives/fall2017/ entries/consciousness-temporal.

Dicey Jennings, C. 2017. I Attend, Therefore I Am. Aeon, 10th July.

Dretske, F. 1969. Seeing and Knowing. Chicago: Chicago University Press.

Gupta, A. 2006. Empiricism and Experience. Oxford: O.U.P.

Hobbes, T. 1651[1966]. Leviathan, or the Matter, Form and Power of a Commonwealth, Ecclesiastical, and Civil. In: English Works of Thomas Hobbes, ed. by Sir W. Molesworth, Vol. III, Londres: John Bodin; second impression in Germany, Scientia Verlag Aalen.

Husserl, E. 1928[2002] Leçons pour une phénoménologie de la conscience intime du temps. Ed. by M. Heidegger in 1928. Paris: PUF.

- 1939. Erfahrung und Urteil. Untersuchungen zur Genealogie der Logik. Ausgearbeitet und herausgegeben von Ludwig Langrebe. Prag: Academia/Verlagsbuchhandlung.

Irving, W. 1921. Rip van Winkle. Philadelphia: D. McKay.

James, W. 1892[1992] Psychology: Briefer Course. New York: Literary Classics of the United States.

Leclerc, A. 2002. Hobbes et le discours mental. Manuscrito XXV(2): 249-269.

Molnar, G. 2003. Powers. A Study in Metaphysics. Oxford: O.U.P.

Rudder Baker, L. 2013. Naturalism and the First-Person Perspective. Oxford: O.U.P.

Principia 21(2): 235-249 (2017). 
Sieroka, N. 2005. Quasi-Hearing in Husserl, Levinson and Gordon. Journal of the British Society for Phenomenology 36(1).

Tye, M. 1995. Ten Problems of Consciousness. Cambridge (MA): MIT Press.

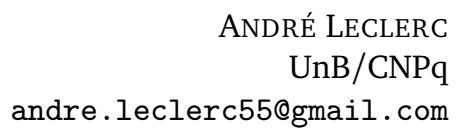

\section{Notes}

${ }^{1}$ Hobbes [1651/1966] is especially interesting on that score among the classical empiricists. "Sentire semper idem et non sentire ad idem recidunt". There wouldn't be sensation at all without the succession of phantasmata in the "mental discourse". See also Leclerc (2002).

${ }^{2}$ See Rudder Baker (2013), where consciousness and the first-person perspective are treated as capacities, and capacities as dispositions, especially on pages $30 \mathrm{ff}$ and pages $172 \mathrm{ff}$.

${ }^{3}$ William James (1961): "Each personal consciousness is sensibly continuous". (p. 153). Also: "Within one personal consciousness, thought is sensibly continuous. I can only define 'continuous' as that which is without breach, crack or division". (p.155).

${ }^{4}$ See Sieroka 2005, p.4: "If our perception would be bound to an infinitesimal point in time, how could we track any melody?” According to Sieroka, Husserl read James' Principles of Psychology.

${ }^{5}$ See Dainton 2008.

${ }^{6}$ See Crane 2009, pp.149-169; especially p.150.

${ }^{7}$ Dicey Jennings (2017).

${ }^{8}$ Dretske (1969).

Principia 21(2): 235-249 (2017). 